\title{
Browsing the Origins of Comic Book Superheroes \\ Exploring WatchMojo.com as producers of video channel content
}

\begin{abstract}
This article tries to explore and explain the significance of comic book superheroes and their origin stories. The article presents an analysis of two selected case examples from the social video sharing site WatchMojo.com. The analysis focuses on four aspects or themes: Comic book hermeneutics, types of origin, subjectivization of superheroes, and user reactions. These analytical themes are based on an approach combining cultural semiotics, comic book superhero studies, studies in participatory culture, cultural studies and media user studies. The analysis provide some evidence to the claim, that superhero origin stories are of significance because its content is relevant to a dedicated number of internet users, and the video content both calls for and creates user reactions. Furthermore this interplay enacts the practice of categorizing and revitalizing as two important mechanisms vital for understanding this particular Internet video content.
\end{abstract}

Keywords: Comic book superheroes, origin stories, comic book hermeneutics, YouTube, WatchMojo.com, Internet video content

What the cloaked and caped conceal: An introduction

Would you like to know how it all began? This question is at the heart of many endeavours in human life, and it is at the core of the subject of this article: Origin stories of comic book superheroes on the Youtube channel Watchmojo.com.

The research interest for this particular subject is, as many things in life, based on autobiography. Why does anybody take an interest in comic book superheroes and stick with that interest through childhood, adolescence and adult life, trying to keep up with an ever expanding universe of heroes and villains, planets and continuity timelines? Why does anybody have an interest in or a passion for fictional beings that are able to do amazing things, and who promises a measure of order and justice? Why does anybody choose to read, follow and interact with imaginary characters that are able to protect and serve, and when necessary even avenge injustice? Why indeed. I believe that the fascination of comic book superheroes have many explanations which are closely connected to societal circumstances and diverse cultural contexts throughout the world. I doubt that the 
experiences of crime and violence in North American urban contexts echoes the same experiences as that of Scandinavian adolescents living in the provincial context of small towns. The fascination of comic book superheroes is an independent subject for research. But an initial claim in this article is that origin stories are important for sense of identity, sense of belonging and for being able to categorize cultural content.

Though this article is about origin stories it will not cover the history (or many histories) of comic book superheroes (eg. Jacobs \& Jones, 1985; Coogan, 2006; Knowles, 2007; Wandtke, 2007; Garrett, 2007). The purpose is neither to cover the chronicling of The Golden, The Silver, The Bronze, The Modern Age or The MultiMedia Age of the caped and cowled protectors and protagonists of a world mirroring the one outside the pages of the comic books. The article is about a small but still important side of the (re)production of the fascination of comic book superheroes that can be framed by the following research questions: Why are Internet users and fans of comic book superheroes (both digital on the Internet, but also "retro style" browsing through digital comic books) interested in how their superheroes came into existence and became who they are? Secondly, how are we to understand the significance of this particular Internet content produced for the commentary video channel WatchMojo.com?

The choice of WatchMojo.com as a case for illuminating and understanding the subject of comic book superheroes and their origins is a matter of personal interest. One interest that originates from frequent interaction with the material over four decades. As for the choice of WatchMojo.com it can be said that the website is neither the most prominent nor the most acknowledged channel on Youtube for the production and distribution of this particular video content. But it displays a certain regularity and appeal. Later in this article WatchMojo.com will be presented in more detail, and it will be observed that superhero origin stories are but one strand in the section of the huge production of commentary materials dedicated to the subject of superheroes (and supervillains) as part of popular culture. In relation to the question "why superheroes and not supervillains", the answer is, that that is another topic for another article. It might be claimed that supervillains as antagonists evoke even more user or fan fascination than superheroes do. It might be the case, and it would certainly merit another investigation into the questions, what are the sources of the fascination for supervillains, and how are we to understand this in the context of both popular culture, society and autobiographies of Internet users. But in this context the argument for choosing superheroes is that they are the cornerstone of the world of comic book superhero publication.

From the Case file: Watchmojo.com as content producer

WatchMojo.com is a Canadian-based privately held producer and publisher of video content on the Internet. WatchMojo.com is currently ranked as the 34th most subscribed channel on the social media YouTube. The validity of the number of subscribers (suggested to be beyond 15 million, 01.01.2017) has not been verified, but it is safe to assume that the amount of subscribers is substantial enough to merit attention. However, the number of users may include "ghost users" so the total number of authentic users may not be the same. 

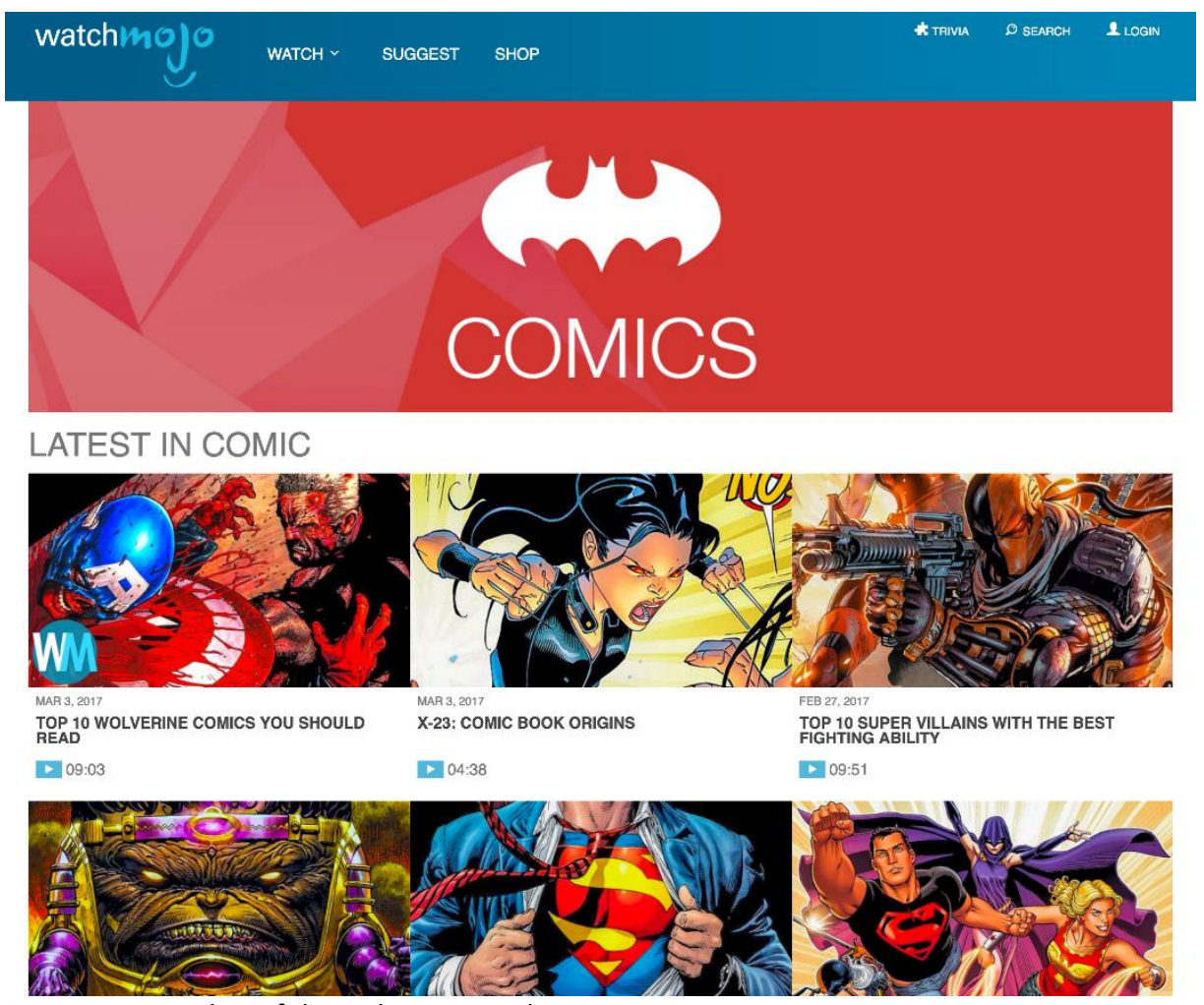

Figure 1: Screenshot of the webpage WatchMojo.com

The Wikipedia article suggests that WatchMojo.com was founded by Karabasfrooshan, Daigneault and Voulieris in June 2005 (Verified 17.8.2017). The areas of content production range from science to fashion, from lifestyle to technology, and from politics to comics. WatchMojo.com brands itself on the daily production of "Top Ten" videos. Some of the "all time" most popular videos include Top 10 Bruce Lee Moments, Most Sexy Female Movies, Most Hated Songs, and Craziest Events Caught on TV (VidStatsX.com). But the interesting thing about WatchMojo.com as site and channel is not the choice of content, which is more or less expected (popular culture is of popular interest). The interesting thing is the sectioning or ordering of cultural content and the logic of hierarchy creating a motivation for viewing or interacting with the content. There will always be persons or events to compare in a Top 10-list manner. This can be done absurdly (the Top 10 of all Top 10 lists), which could be understood as either irony or satire, but instead underlines what creates part of the fascination: How does the world rank content such as comic book superhero characters, and how similar or different is the individual user's reception of these rankings or the interpretations of origin stories.

In this context no elaboration on YouTube as the communicative and Internet-based infrastructure for WatchMojo.com will be carried out. An element of interest in relation to the users could be if the sign-in user profile on WatchMojo.com is the same as or converging with the possible user profiles on YouTube. This element has to do with the significance of the user's identity. In the section following Burgess \& Green's work on YouTube as a new media environment will be mentioned in relation to understanding the flow of the cultural circuit of the Internet (Burgess \& Green, 2009).

At this point it is relevant to clarify why there is a need to understand the subject of comic book superheroes scientifically. One aspect is that comic book superheroes constitute a large segment of the production of popular cultural content, and it has created a world wide fan-based community events such as Comic Con, and further it spawns a steady stream of fan-based produced video content. But why is this interesting from a scientific perspective? 


\section{The Lair: Theoretical framework and perspective}

In this part of the article concepts and considerations relevant to the study of comic book superheroes and shared video content on the Internet will be presented. Comic books and comic book superheroes have been considered a serious academic research area for quite some time (Strömberg, 2016; Beaty \& Woo, 2016). Part of this acknowledgement can be identified in cultural studies, popular culture studies, gender studies and fandom studies. These are published in international journals such as Journal of Graphic Novels and Comics (Routledge), Journal of Comics and Culture (Page University Press), Pelgrave Studies in Comics and Graphic Novels (Palegrave Macmillan), and Studies in Comics and Cartoons (Ohio State University Press). Further scholarly studies in comic books and superheroes are published in a variety of art related journals (eg. Journal of Visual Arts Practice, Taylor \& Francis). But the scholarly interest in comic book superheroes did not begin with acknowledgement but with grave consideration and worry: Comic books and indulgence in superheroes corrupt the minds of the younger generation (eg. in a danish context, Haxthausen, 1955).

It would be wrong totally to dismiss any sceptical approach to comic books and comic book superheroes especially in relation to the theme of moral panics or moral media panics (Cohen, 1987, Drotner, 1999). The Slovenian philosopher Slavoj Žižek notes in many of his critical studies of contemporary culture, that comic books and comic book superheroes by far are neutral zones of experience but rather structured and weaved with threads of capitalist ideology and political moral dispositions (Žižek, 1989, 2000). But taking comic book superheroes serious as a field of inquiry does not imply that the research should celebrate and rejoice the status of the object, that it has been acknowledged. Rather it is an opportunity to understand how comic book superheroes play a part in both human (media) history and as a cultural way of expressing human fears, reflections and hope. In a slightly different tone, but in the same vain, American scholar Will Brooker notes:

In the wake of cultural studies, the proposition that superheroes merit our attention will probably be granted readily enough. The genre, both on the page and on the screen, is widely understood to be ideologically freighted: a mirror, and perhaps a shaper, of cultural and moral values. The study of such things can take either an adversarial or sympathetic stance, depending on the researcher's perspective. However, the claim that superhero comics can reward close study on formal and aesthetic grounds remains controversial, even among scholars who have committed their careers to the study of comics more generally. A warrant on the grounds of aesthetics, form, or genre poses different questions than one based on sociological and political concerns. A number of prominent cartoonists and comic book writers, notably Art Spiegelman and Harvey Pekar, but also others, have concluded that the superhero genre is essentially fascistic and/or absurd and therefore deserves a pitiless shellacking. This would still be a form of seriousness. (Brooker, 2013, p. XIV-XV)

In the same article Brooker helps us distinguish between comic books and superhero comic books by underlining:

Superhero comics are not the same thing as comics per se, but they are integral to the development of the American comic book, and therefore to the history of the form. Admittedly, the genre has roots outside of comics: antecedents for the superhero can be traced back through pulp literature to ancient myths and legends, what Joseph Campbell called "the basic images of ritual, mythology, and vision" (18). But superheroes are intertwined with comics history to an extent that is not true of other major multimedia genres such as science fiction, horror, romance, or the western. All of those genres, and more, have been very important to comics, but the superhero stands apart. From the standpoint of English-language comics, at least, the superhero is not just another genre, but one that has made all the difference. (Brooker, 2013, p. XI-XII)

For Brooker it is the visual form and not the form of the narrative that defines the superhero comic book. The question of the form of the narrative is something that the late semiotician and cultural scholar Umberto Eco deals with in his exploration of the structure and pragmatics of closed texts, and with explicit reference to Superman (Eco, 1984):

The hero equipped with powers superior to those of the common man has been a constant of the popular imagination (...) Often the hero's virtue is humanized, and his powers, rather than being supernatural, are the extreme realization of natural endowments such as astuteness, swiftness, fighting ability, or even the logical faculties and the pure spirit of observation found in Sherlock Holmes. In an industrial society, however, where 


\begin{abstract}
man becomes a number in the realm of the organization which has usurped his decision-making role, he has no means of production and is thus deprived of his power to decide. Individual strength, if not exerted in sports activities, is left abased when confronted with the strength of machines which determine man's very movements. In such a society the positive hero must embody to an unthinkable degree the power demands that the average citizen nurtures but cannot satisfy. (Eco, 1985, p. 107)
\end{abstract}

It is most likely that Eco would have agreed, that the viewers and fans of comic book superheroes today are not solely depowered numbers in an industrial society. The impact of fan communities and networks of co-creating actors (Jenkins, 1992, 2006) do indeed constitute a cultural power that both market and civic society acknowledge. Whether any critical analysis of the asymmetric power relations between societal institutions and the individual, as Eco points out, still holds today, is another subject for another investigation. Eco's semiotic analysis of the poetics of the closed text and the character and paradoxical plot opportunities in the comic book textuality do not follow that line of inquiry. But it is without doubt that Eco tried if not to redeem popular culture and its content, then at least to recognize it because of the basic poetic similarities with other cultural content and phenomenas.

Eco's semiotics is relevant in this context because of his notion of the Model Reader. Eco develops this notion in no small part inspired by the notion of "the interpretant" as formulated by American pragmatist Charles Sanders Peirce (Eco, 1984). Eco defines this semiotic concept: "(...) the Model Reader is a textually established set of felicity conditions (Austin, 1962) to be met in order to have a macro speech act (such as a text is) fully actualized." (Eco, 1984, p. 11). Why is this relevant to the (re)telling of comic book superhero origin stories? Eco's point is, that any text that follows a strict set of conventional and canonical lines in relation to plot and character needs the reader to activate his iterative and narrative competence in order to (re)invest himself in something that is both repetitive and expected. In other words in order to move forward in the imaginary world of the comic book superheroes, the reader or the user needs to go back to find the possibilities in the origin of the character and the potential story lines. This is, as an academic claim, what Watchmojo.com offers the user: To go back to the beginning, and at the same time recognize that any fixed plotline can be iterated, changed, and thus revitalise the specific comic book superhero, and the comic book world of superheroes. Even though the map of the comic book superhero world is just as canonical as so many other examples of "closed textual" pieces of literature.

In Cultural Studies (eg. Fiske, 1987) a central mechanism of popular culture is the circuit of intertextuality and cultural (re)production. This mechanism distinguishes on one hand between the level of production, circulation and consumption of cultural products and content, and on the other level of audience engagement in first, second and tertiary intertextuality. The first vertical level of intertextuality is the level of media industry production (eg. the news, the movies, the tv-series, the computer game). At this level structures of format, ownership and regulation are of academic interest. The second level deals with the production of industrial and professional commentary, but also gossip and "back stage" stories of the actors or agents of the content and narratives in the intertextuality on the first level. The third level of intertextuality represents the interactions between users and fans as part of "the audience". Creating a YouTube channel with the purpose of sharing your observations and personal views on certain topics (eg. movies, fashion, technology, music) can be considered tertiary intertextuality. In this context it is not relevant to consider videos with (hazardous) experiments, design or redesign of products (eg. nerf toy weapons) as representing a tertiary intertextuality. But the point is that for something (a video, a net-based product) to be part of the intertextual circuit, it needs to refer explicitly (or at least not too concealed) to the "nexus" of the circuit.

The cultural circuit, of course, needs some basic infrastructure, and this structure is currently the Internet. Part of this is the web services offering free sign-on platforms with the possibility of sharing the user's own content. In the case of YouTube the Internet users are offered a video-based content sharing service. In their academic analysis and exploration of YouTube as new media in a participatory culture, the researchers Jean Burgess and Joshua Green point out, that as an infrastructure YouTube is characterised by its ability to host both corporate media industry and the force of the "amateur" or the "pre-fessional" creators of video content (Burgess \& Green, 2009). In this sense YouTube constitutes a public sphere that enables both market actors and individual users to 
share their content and expressions. It is possible to see this as a convergence or delevelling of the cultural circuit of intertextuality. In the case of comic book superheroes as content, the ownership of the core of the franchises are still part of the primary intertextuality, but this level cannot exist without the close convergent nature of the whole circuit. The re/tellings of comic book superheroes origin stories play an important part of the marketing and the refining of the media industry production.

In order to further understand the form and function of narrative in comic book superheroes origin stories it is possible to continue to consult the theory of structuralism and semiotics. However, another possibility is to approach the question of the form of re/telling form from a more genre-based perspective.

In her book "Superheroes! Capes and Crusaders in Comics and Films" British writer and critic Roz Kaveney outlines a comparison between comic book superhero stories with opera. Kaveney points to:

\begin{abstract}
Both are radically impure forms based on some fundamentally absurd conventions; both are irritating if one does not develop a taste for preposterous rodomontade and brightly coloured costumes. Both of them can do certain things that other art forms can only do with great difficulty; comics and opera can slow narrative time down while moving it forward at a steady pulse, without having necessarily to indulge in the dreamy floatiness of slow-motion photography. Both can give you, effectively and without implicit comedy, the thought processes of both parties in a dialogue, or a clear sense of what everyone is saying at the same time in a complex scene. Both are also concerned to show us gods and heroes and monsters, male and female, in all their power and dignity, but also with all their passionate emotional human intensity. Both, accordingly, have a tendency to inflate language into something that can become bombast, or can be more charitably seen as a necessary, if sometimes loopy, grandiloquence commensurate with the scale of what is sometimes portrayed. At their best, both can portray immense emotions played out on vast canvases, and yet be capable of dropping to pianissimo in a second when it is needed. (Kaveney, 2008, p. 22f)
\end{abstract}

In these passages the melodramatic nature and contours of comic book superhero stories become clear. Kaveney continues to point out similarities to opera such as cultural forms are commercial works of art or artistic endeavours, and both are minority art forms in which the spectator or user is able to develop certain nerd-like expertise (eg. being an expert on something with a very small audience). Of interest to the subject of comic book superhero origin stories is, as Kaveney points out, that due to the expanding nature the narrative universe of diverse continuities (eg. Marvel and Detective Comics/DC), the spectator or the participatory user needs origin stories. Not least to navigate between "lore and legend" and to be able to evaluate the representational and narrative quality of this particular cultural content.

\title{
Gadgets and devices: Methodological reflections
}

In the first section of this article WatchMojo.com was introduced very briefly. One aspect that needs to be addressed is the selection of WatchMojo.com. As mentioned the selection was based on autobiographical interest. It was the first site for comic book superhero video commentary that the author encountered. But there are many other notable channels on YouTube that share similar interest in popular culture and comic book superheroes: VirantComics, Comicisland and WhatCulture, just to name a few. It is in this respect that the interest is not merely subjective, but aims at creating insights and possibly to contribute to a generalization about what it is that makes comic book superhero origin stories culturally meaningful.

One of the distinguishing features of WatchMojo.com is, that the videos do not have a recurring host. Instead WatchMojo.com uses an authoritative voice over. The function and significance of this may be a matter of strategy. But without an independent exploration of the communicative strategy for the different channels it will remain an assumption whether the lack of using a visible and recurrent host in the videos is chosen due to a consideration of the total "flow" of video circulation. It can be argued, that if the content area is diverse, it is a matter of resources in relation to employing hosts. Can the same host cover content areas ranging from both sports, technology, lifestyle and comic books, if the host is easily and visibly identifiable? Or is it more "economical" to use voice-overs in order for the same team to cover a enormous diverse area of content? 
Another important methodological consideration is how to "read" or analyse video content in the context of YouTube. As mentioned in the previous section it is possible to focus either on visual form and format, narrative form, or even user comments. Of course the analysis of video content on the Internet can be analyzed in many other ways, both qualitatively and quantitatively. The analysis in the next section of the article will focus on four elements: Comic book hermeneutics, types of origins, subjectivization and user reactions. These elements will be explained in the next section.

A third methodological reflection is the selection of material or data. In the aforementioned Wikipedia article presenting WatchMojo.com it is stated, that the channel produces daily commentary videos since January 2007. According to WatchMojo.com's own statistics the grand total to date is 14,779 videos. According to playlist information on WatchMojo.com only 120 are about superhero origin stories. It is not possible to ascertain what section the superhero origin stories belongs to, and therefore it is not possible to evaluate any quantitative status. But it is safe to say, that comic book superhero origin stories are not the predominant content in WatchMojo.com's video content portfolio.

A fourth methodological reflection is the selection of the actual case material. This selection is once again based on autobiographical interest and interaction with the content on WatchMojo.com. The actual videos selected are the origin stories of the character Batman and Green Arrow from the DC universe. It may be considered a bias that two male characters are chosen. It can be argued that due to gender there might be differences in the type of origin story. This consideration is relevant to another study with focus on gender and superhero fan culture.

A fifth methodological reflection concerns the categorization of user reactions to the chosen comic book superhero origin stories. Categorizing Internet postings of users can be done in both a formal and a substantial way as considered in the empirical Grounded Theory approach (source). One formal way of categorizing user reactions would be to follow the approach presented by Danish fandom scholars Thessa Jensen and Peter Vistisen (Jensen \& Vistisen, 2013). They propose to categorize user reactions to Internet content (on YouTube) in a grid consisting of two dimensions: +/- serious, +/- constructive. Another way to categorize user reactions to YouTube content could follow the lines of Internet fandom scholar Nancy Baym's suggestion to distinguish between interpretive and informative practices (Baym, 2001). In her important study of soap opera fandom, Baym proposes to categorize user reactions in interpretive terms (personalization, character interpretation, speculation) and informative terms (updates, spoilers, trivia, sightings).

Inspired by these academic ways of dealing with user reactions as data in scholarly inquiry, I have developed a Pentagon with which to distribute and understand user reactions to the comic book superhero origin stories. The ambition of the Pentagon is to try to be sensitive to the emotional dimension (eg. passion, taste, distaste, admiration, disgust) of user reactions to particular Internet content. The Pentagon distinguishes between user reactions that are:
a. Celebrating (cool stuff!),
b. Elaborating (do you know that),
c. Speculating (what if, or what is the meaning),
d. Critical reflecting (please consider, and maybe we need to employ irony), and
e. Disawoving (this is stupid stuff).

As stated the Pentagon was developed in part by inspiration from the fan studies mentioned, with an ambition to capture the diverse nature of user reactions in a way that focus less on pro et con, and more on the dynamics of the interaction between users in the posting section. It seemed obvious that an analytical framework with five categories could take the form of a Pentagon. 


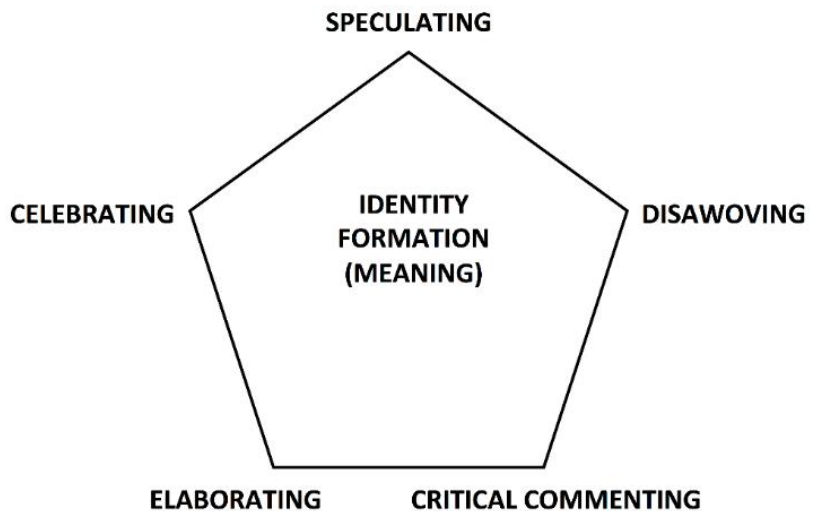

Figure 2: The Pentagon of user reactions

The analytical point of the Pentagon is not only to categorize user reactions in an innovative way, but emphasising that the meaning of the user reactions is about forming identity. It is a separate study to unfold the diverse nature of "identity" in relation to Internet content and user interactions. But the point in this context is that the user reactions based on the users' interaction with each other become meaningful because the users not only state taste based opinions, but establish a meaningful space created by their interactions.

As a final methodological reflection, we turn to the data or the empirical source of the study. The following figure is a very short presentation of the selected comic book superheroes videos in focus.

\begin{tabular}{|l|l|l|}
\hline & \\
& Batman & Green Arrow \\
\hline Posted/duration & Mar $23,201506: 15$ min. & 1,029 mio. \\
\hline Views & 0,557 mio. & $5,981 / 68$ \\
\hline Likes/Dislikes & $7,781 / 98$ & 1,285 \\
\hline Comments & 1,046 & min. \\
\hline
\end{tabular}

Figure 3: Comic Book Superhero origin video content selected from WatchMojo.com (current figures)

In the article the two origin video narratives will be presented with focus on how WatchMojo.com tells a comic book superhero origin story, and how this form is standard, and how it draws on and mixes references to the overall popular cultural world of comic book superheroes.

Patrolling the battlefield: Interpretation of the superhero origin stories

In the theoretical section of this article Umberto Eco and Roz Kaveney were used to propose ways of interpreting the meaning of comic book superhero origin stories. Burgess and Green were used to indicate that the circuit of cultural content is supported by the Internet and video sharing sites such as YouTube. In this section of the article four analytical points will be presented, all dealing with the question: How are we to understand what it is 
WatchMojo.com does in relation to Internet content on comic book superheroes, and what does it mean in relation to user reactions?

\section{Comic book hermeneutics}

The recurrent introduction to the superhero origin stories on WatchMojo.com stresses, that even though we are dealing with fiction and fictional characters with many "canonical" readings, the determination of the single superhero is still a matter of interpretation. All the videos begin with the following introduction:

Welcome to watchmojo.com. And today we will explore the origins of (the superhero). Before we begin, we publish new videos every day so be sure to subscribe for more great content. As with most comic book characters there are often reimaginings and different versions to a character's past. We have chosen primarily to follow the storyline which unfolded in (name and number of comic books). (WatchMojo.com)

As in all cases the Model Reader of a specific text, or in this case the net-based medium, is expected to have certain competences and knowledge of the primary intertextual level of the cultural content circuit. The origin videos do not expect the Model Reader to possess the knowledge of the specific materials that serve as evidence for the presented interpretation of the specific origin story. What this format offers the actual viewer is both the opportunity individually to seek out the issues of the comic books used to produce the interpretation. At the same time WatchMojo.com presents itself as a kind of authoritative source or guide to the origins and backgrounds of the superheroes in question. However, this authoritative position is framed by a sort of "hermeneutical humility" ("we have chosen") resonating the reflexivity of any late modern attempt to grasp and to explain any case or subject at hand.

An element in the construction of the origin stories of the superheroes is the use of cross media materials. In relation to the two selected origin videos this is true of Gotham's stoic protector, and to a lesser degree in the case of $A$ modern day Robin Hood. In the course of the Batman origin video the explicit reference to and use of clips from the cinematic adaptation are presented mixed with the standard animated flow of comic book frames and pages. Here the story of the character Batman is visualized by Tim Burton's gothic version (Batman, 1989, Batman Returns, 1992, both Warner Brothers), and Christopher Nolan's action enhanced version (Batman Begins, 2005, The Dark Knight, 2008, The Dark Knight Rises, 2012, Warner Brothers Pictures, Legendary Pictures). The significance of this element is that it presents the viewers or YouTube users with a possible connection between the different cultural content (comic book, movies). As such this expands the basis for the continuities that Kaveney points out creates the necessity for origin stories itself. New cultural content needs to be assessed in order to be useful in the ordering and understanding of the individual superhero in the relevant comic book universe and continuity.

Turning to the two selected superhero origin stories some basic WatchMojo.com information has already been mentioned (figure 2). For the purpose of understanding the hermeneutics of the comic book superheroes the following figures include an example of how the issues of understanding the origin were presented in the "original" comic books (both from the Bronze Age of comic book superhero, Jacobs \& Jones, 1985). 


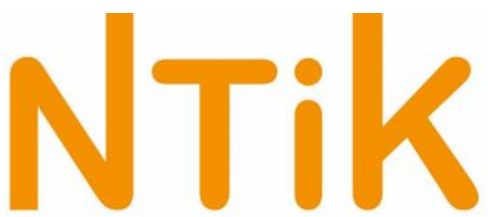

Nordisk Tidsskrift for Informationsvidenskab og Kulturformidling

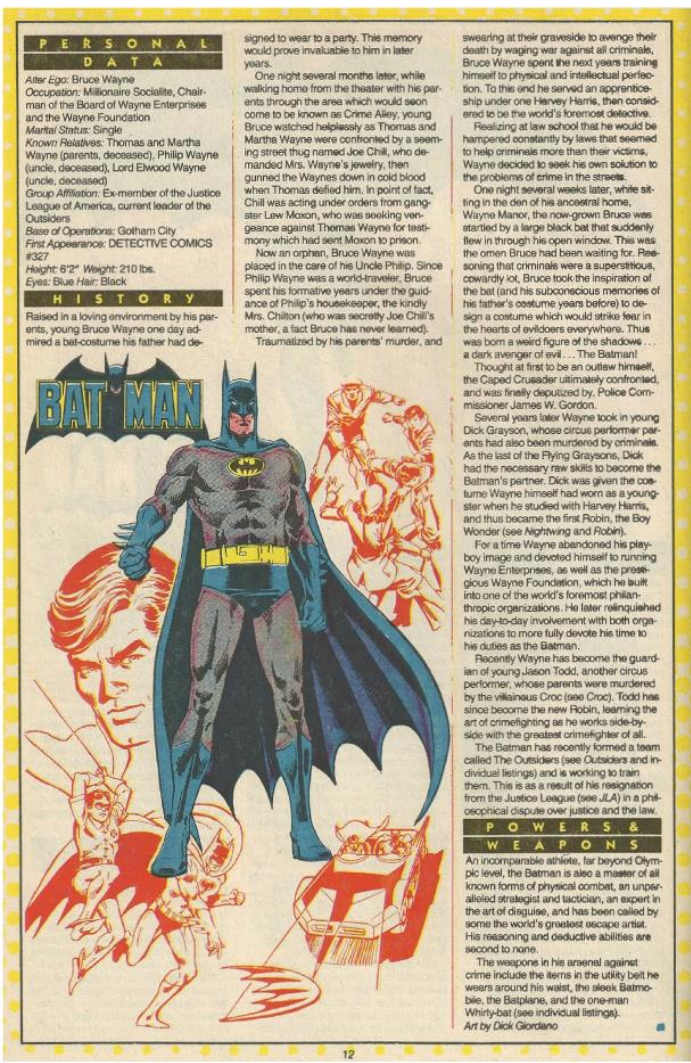

Batman of the Bronze Age (1970-1985).

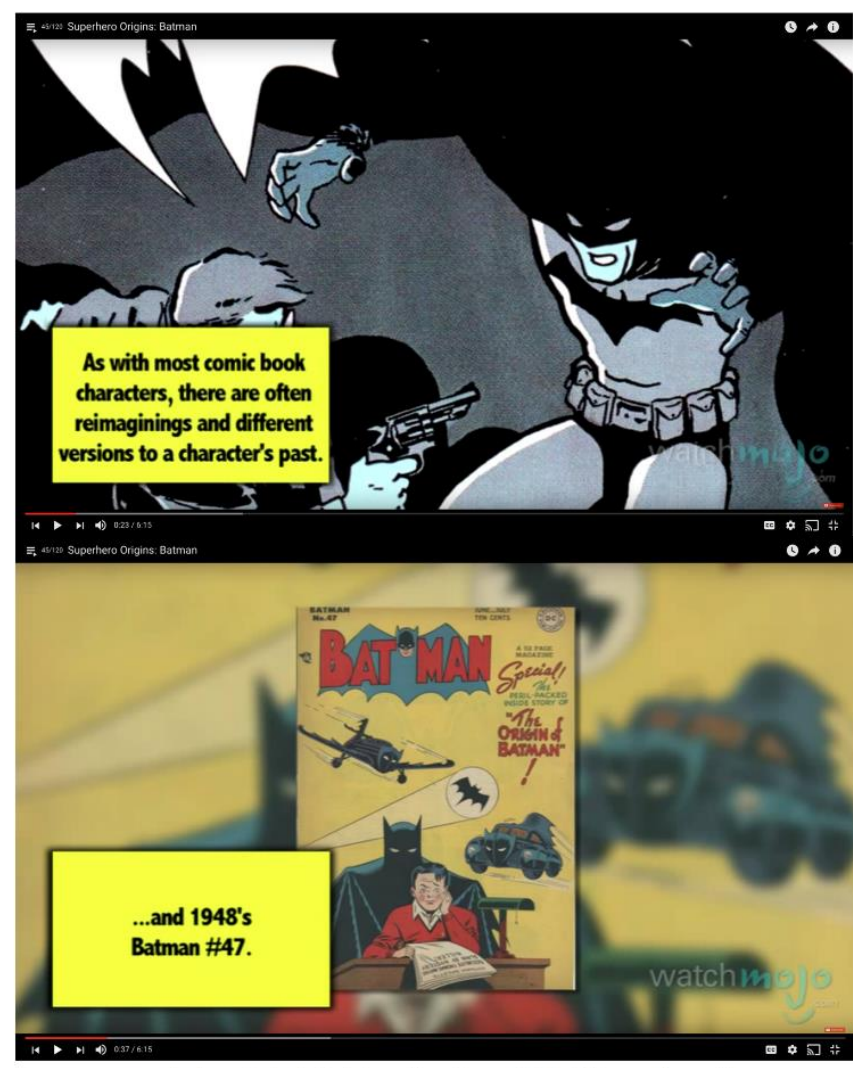

Batman of the Multi-Media Age (2005 and on)

Figure 4: The stoic protector of Gotham, Bruce Wayne

In the case of the comic book superhero Batman one of the differences between the two forms of origin stories is the visualization of the intertextual background for the interpretation. The comic book form focuses on "Personal data", "History" and "Powers and weapons". As such it is presented more authoritatively and insists on a rather closed reading of the character. This can easily be explained by pointing to historical circumstances for the comic books of the Bronze Age (Coogan, 2006). The circulation and sales of the superhero comic books were receding, and even though the first generation of computer games at the time also included versions of the superheroes, the low interactive possibilities of the analogue comic book may have lost to the emerging digital gaming culture. But the point is, that the "tone" of the WatchMojo.com presentation of the origins is less authoritative, as mentioned earlier in this article.

Turning to the superhero origin video of Batman, WatchMojo.com presents the well-know story of young Bruce Wayne, billionaire and protegé to the Wayne business. Bruce's parents Martha and Thomas Wayne are murdered by a gangster and this traumatizes Bruce deeply. In the video one origin revision is presented. In this, young master Wayne returns to Gotham City after twelve years abroad trying to deal with the lost of his parents. The revision is not interpreted in relation to the overall storyline or any changes in the character. If we look thematically at the video it follows a flow: From the trauma, the training, the choice of symbol, the confrontation, the closure, the team ups, the revision, the villains, the abilities and gadgets, the crossmedia appearances and interpretations (the many screen faces of Batman). As a punchline two movie quotes are used from Christopher Nolan's cinematic interpretation of the character (Batman Begins, 2005). The one is the Joker stating to Batman: You truly are incorruptable! The other the ending dialogue between Commissioner Gorden and Batman: Gordon: I never said thank you. Batman: And you'll never have to! 


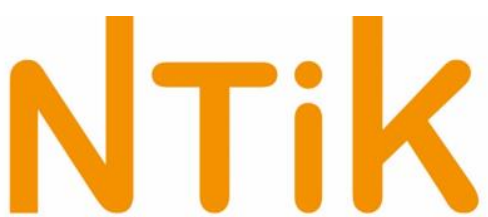

Nordisk Tidsskrift for Informationsvidenskab og Kulturformidling

Later in this article selected user reactions will be presented in order to understand some of the participatory elements of the fascination of the origins videos presented on WatchMojo.com. But one reaction that cross both the postings related to the two videos is, that Batman and The Green Arrow share many similarities, with explicit user comparisons.

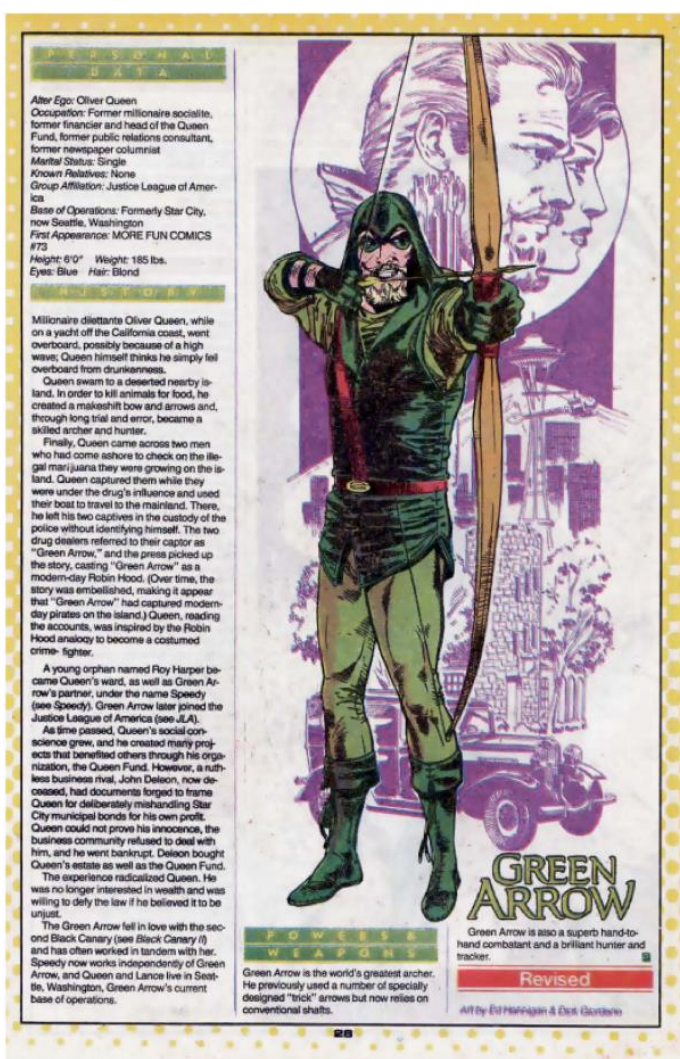

Green Arrow of the Bronze Age (1970-1985).

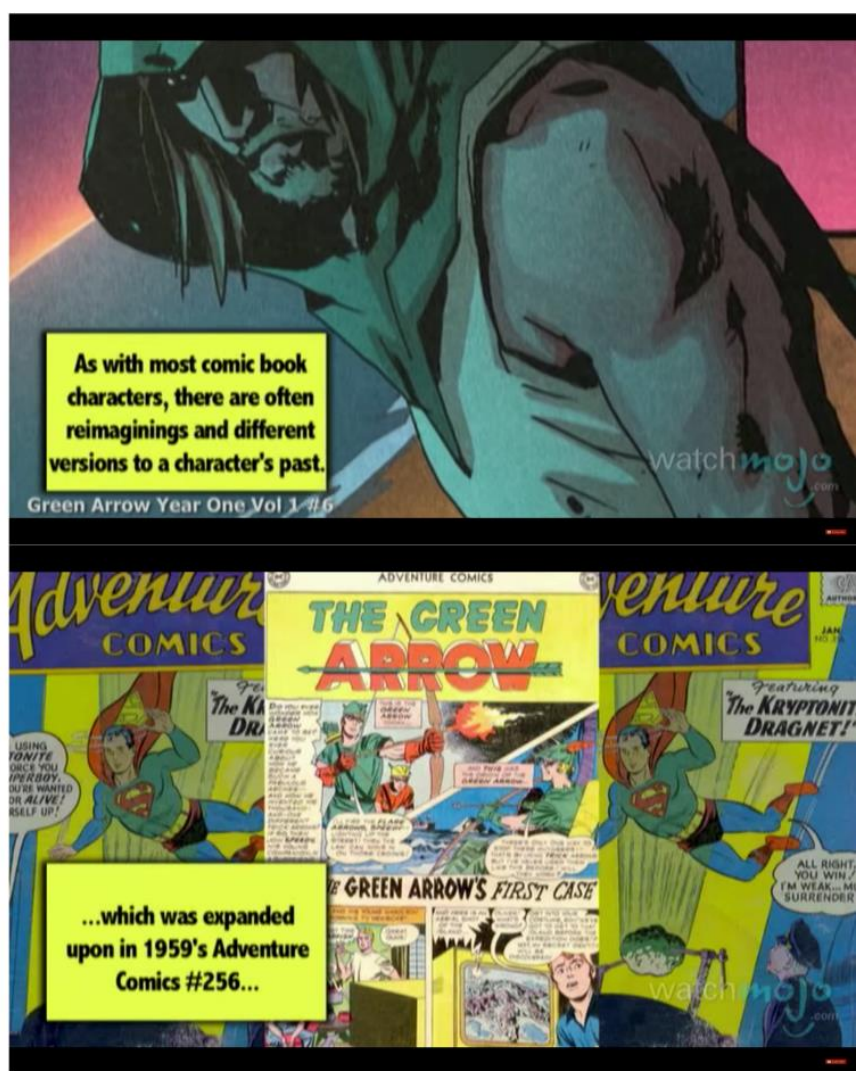

Green Arrow of th Multi-Media Age (2005 and on)

Figure 5: The moden day Robin Hood, Oliver Queen

As with the Batman origins video The Green Arrow narrative is presented in a flow taking the user from the first appearance in the DC comic book franchise to the present cross media interpretations. The Green Arrow starts out with his sidekick in red, Speedy. He is presented as an orphan millionaire, Oliver Queen, who is marooned in isolation on an excotic island. On this island he develops his archery skills in order to survive by hunting. The video explains how Queen develops his trick arrows, and his green costume. Both become helpful in a mutiny conflict on a ship passing the island. Queen assists the ship's crew with subduing the mutineers, and as a result he returns back to his home city. The video then explains one revision in which Queen ends up on the island due to a betrayal from a friend. On the island Queen encounters a group of druglords, with the same result as the first storyline. In the revised storyline Queen sheds his fortune because of moral considerations and the fact that his company manufactures weapons. Then the many appearances in various media (tv-series, cartoons) is presented, and it is noted, that The Green Arrow is the most left wing character of the DC universe. The video punchline is a quote from the Warner Brothers cartoon series Justice League, in which The Green Arrow asks Batman the reason why his is part of the superhero team: The Green Arrow: Still don't think I belong up here? Batman: That's the point. Someone like you will keep us honest!

Both the comic book version and the WatchMojo.com version of the origin stories offer the users of the channel an opportunity to let the past and present of the characters merge into a coherent if not singular storyline. The content provides material to understand the motivation of the characters as well as identifying (as Eco points out, 1984) with the types of origin stories presents. The choice of the two superhero origin story videos was not 
motivated by any intention of comparing the two, and let alone compare the superheroes, but instead to showcase how the form of the videos gives the users a if not authoritative explanation of the past and present of the character then a rhetorical outset to understand what made and molded the superheroes into what they are. One element that the videos do not reflect is the overall changes in the historical context of the comic book superheroes and the different thematic and ideological dimensions in the different ages of the world of comic book superheroes (Coogan, 2006, Duncan et al, 2015). This topic is beyond the scope of this article, but the observation points to the possibility that the message of the origins stories on WatchMojo.com is both fascination (love your favourite comic book superhero) and interpretation (do you agree with our attempt at establishing character). From a ritualistic view of communication the user of the channel is offered the "model user" position of taking part in the revitalising of the character and the universe of comic book superheroes, by giving the users a fixpoint in a steady and ever growing production of comic book superhero content by both the cultural industry and other fan based participations and contributions.

\section{Types of origins}

Even though the aim of this article is not to outline a complete list of types of origins in relation to the total amount of material on Watchmojo.com, a provisory list of categories is compiled to help understand that side of the matter. As the two videos explain all origins do not derive from trauma alone. A more valid list of categories demands a more thorough analysis of the material. However, based on a preliminary study it is possible to categorise the following seven types. In this table several of the 120 superheroes characters presented with origin videos on WatchMojo.com are included.

\begin{tabular}{|l|l|l|}
\hline Origin type & Marvel & DC \\
\hline $\begin{array}{l}\text { Extraterrestial } \\
\text { Subterreaneal } \\
\text { Mythological }\end{array}$ & Namor, Thor, Hercules, Silversurfer & $\begin{array}{l}\text { Superman, Aquaman, Wonder } \\
\text { Woman, Martian Manhunter, } \\
\text { Hawkman, Hawkgirl, Starfire }\end{array}$ \\
\hline Ordeal & Punisher, Iron Man & Batman, Robin, Arrow, Black Canary \\
\hline Mutation & $\begin{array}{l}\text { Professor X, Wolverine, Storm, } \\
\text { Psyclops, Phoenix, Nightcrawler, } \\
\text { Beast }\end{array}$ & $\begin{array}{l}\text { The Elongated Man } \\
\text { Cyborg }\end{array}$ \\
\hline Accidents, toxic, raditation & Daredevil, Fantastic Four, Spiderman & The Flash, Firestorm \\
\hline Experiments & $\begin{array}{l}\text { Captain America, Wolverine, } \\
\text { Deadpool, Luke Cage }\end{array}$ & Black Panther, Green Lantern \\
\hline Inherited & Doctor Strange, Iron Fist, Blade & Arsenal, The Atom, Booster Gold \\
\hline Military & $\begin{array}{l}\text { Black Widow, Nick Fury, Ant-Man, } \\
\text { Vision, Iron Man, Falcon }\end{array}$ & \\
\hline
\end{tabular}

Figure 6: Types of origin stories

Looking at the two selected cases, Batman and The Green Arrow, they share a similar and not yet quite similar origin in the videos. Both heroes experienced an ordeal. Batman witnessed the murder of his parents, The Green Arrow was marooned on an island, left alone and would have been dead if not keen on surviving and returning to his home. In both cases the type of origins presented provides the user of the channel with the possibility of understanding some of the many paths that the comic book universe (including the crossmedia versions) outline for the superheroes. Another point of the differences in the type of origin is that it gives background for understanding the motivation and the intensity of the motivation that drive the superheroes to act as presented in the storylines (justice).

In the selected videos the type of origin of the superhero is not commented on in any way to assess the gravity or depth of the specific origin. One reason for this could be that many of the characters have mixed origins, and that this provides for the production of new and more refined or elaborated versions and mentions of revision 
in new origin stories (Wandtke, 2007). Another point of relevance in relation to the type of origin is that the specific origin reflects certain societal issues that either are a concern of the time, or part of more specific global themes (such as radiation, mutation, ethnic diversity).

\section{Subjectivization of superheroes}

Presenting an interpretation of the origins of the comic book superheroes provide the user of the channel with an understanding of the motivation of the heroes, and maybe also a possible acceptance of the actions and special methods chosen by the characters.

In some of his comments on late modern culture and how ideology works in contemporary society Slovenian philosopher Slavoj Žižek makes the observation, that comic book superheroes in the beginning were consumed and legitimized because of their function (ensuring a measure of moral order and peace in a world with threats and risks such as crime, war and natural catastrophes). Even though Žižek has not commented directly on any superhero origin story video (though he has commented on both the cinematic versions of Spiderman, Superman and Batman), he would insist that comic book superheroes served a functional purpose in their early form, and that is function had a purpose and a usefulness. For Batman this means pointing out urban violence and the problems of having to live with a dual identity. The subjectivization of superheroes (a term borrowed from German professor Thomas Ziehe, Andersen 2012) presents us with a problem that the purpose of (super)human actions needs to be legitimized in the context of the individual superhero biography. For Žižek, this constitutes a problem and a bad shift in political focus confronted with the risks and dangers of late modern life. For Žižek, it is misguided to believe that the world will be better and safe place, if the individual tries to find the motivation in his or her own biography and biographical circumstances as mirrored in the comic book superhero stories. Žižek states that this turn in understanding the late modern individual and its possibilities of acting on crisis or ordeals is part of a liberal ideology. This is a problem because it does not fully recognize the necessity of collective action on a structural level.

Even though that the comic book superhero origin videos focus on the individual character and elaborate on the specific superhero biography, there is no indication or thematization that the model for solving problems (presented in fictional form) is based on the principle of "understand thyself". The selection of materials for this article fails to demonstrate, that WatchMojo.com also includes origin videos of teams, and these videos implicitly stress that problems and crisis need a collective and a joint effort in order to create better conditions for living in a precarious world. Žižek would probably insist that these teams of superheroes work outside government, understood as the manifestation of collective will to act, but as further investigation could show many of the superheroes have tried to work inside government jurisdiction. Even Oliver Queen ran and was elected for office in his fictional home city. The meaning of this in relation to the origin videos is that there is an ideological dimension that users of the channel may not be aware of.

The point of subjectivization in relation to comic book superhero origin stories then is, that they do not reflect this theme, even though current portrayals of superheroes in both comic books and other media versions (in both cinematic and series formats) exactly present superheroes as ordinary people, with issues of family, friends, spouses, and everyday problems as diverse as unemployment and sexual orientation.

\section{User reactions}

The last analytical aspect of this article on comic book superhero origin story videos is about user reactions. This is relevant because of the nature of social media and the overall participatory culture in which many social media on the Internet are embedded. Without user reactions the point and relevance of the content becomes meaningless. As mentioned the videos contribute to ongoing revitalising of the characters and on the same time provide the franchises the possibility of continuing the creation of new continuities, thus creating value in that section of the market of popular culture.

As shown earlier the two selected videos have more than 1,000 comments in the thread section of the individual video. The focus of this article is not to claim that this amount of comments is part of the definition of superhero 
origin videos. It seems likely that some superhero origin videos have received much less user commentary and reactions. This could be the case of less know superheroes (eg. the Creeper).

In the actual case of the selected origin videos the reactions of the users can be categorized in the following five categories, as developed and reflected in the methodological section of this article (the Pentagon model).

\begin{tabular}{|c|c|c|}
\hline $\begin{array}{l}\text { USER } \\
\text { REACTIONS }\end{array}$ & $\begin{array}{l}\text { BATMAN } \\
\text { Posts: } 1,046(23.3 .2015-19.3 .2017)\end{array}$ & $\begin{array}{l}\text { THE GREEN ARROW } \\
\text { Posts: } 1,285(5.9 .2012-19.3 .2017)\end{array}$ \\
\hline CELEBRATING & $\begin{array}{l}\text { "I love Batman" (Ashu Prak) } \\
\text { "I LOVE Batman hes sooooooooooooooo cool." } \\
\text { (Anabella's Channel) } \\
\text { "Batman is the best superheroes ever." (Chimi } \\
\text { Changas) } \\
\text { "Awsome video dude! And i AM BAT FAN." } \\
\text { (GAIUS WRIGHT) } \\
\text { "Batman > Everything else." (Nick Arriaga) }\end{array}$ & $\begin{array}{l}\text { "This is origin is obviously the superior for one } \\
\text { reason. Oliver's character in general. He's not } \\
\text { som batman narcissistic guy who wants } \\
\text { revenge. He's a Robin Hood character, fighting } \\
\text { for the little guy in whatever way he can." } \\
\text { (AnimateN8) } \\
\text { "Great job, watchmojo! Now do an origins on } \\
\text { Black Canary!" (Ramon Perez) }\end{array}$ \\
\hline ELABORATING & $\begin{array}{l}\text { "Favourite Batmans: 1. Kevin Conroy, 2. Michael } \\
\text { Keeton, 3. Ben Affleck." (Bananaminionz) }\end{array}$ & $\begin{array}{l}\text { "Green Arrow and Batman are really similar." } \\
\text { (Solomon Grundy) } \\
\text { "I just wish that he had trick arrows in his live } \\
\text { action series Arrow." (Sesshomaru) }\end{array}$ \\
\hline SPECULATING & $\begin{array}{l}\text { "One QUESTION! I'm looking forward to anyone } \\
\text { who answers this. Okay, here goes! WHY doesn't } \\
\text { Bruce Wayne create a superserum? He is highly } \\
\text { intelligent to do it so why doesn't he create it } \\
\text { and become a superhuman? He is mortal but all } \\
\text { that brute strength that super high IQ of his, it } \\
\text { would only benefit him and make him even b } \\
\text { etter and that isn't saying a lot." (JIROU NEGRO) }\end{array}$ & $\begin{array}{l}\text { "it is just me or was it kind of pervy when } \\
\text { Batman was just casually waiting for Green } \\
\text { Arrow to come out of the shower ... he was } \\
\text { against the wall chilling like ... 'Welcome to the } \\
\text { team ..."' (BigDapPacino) }\end{array}$ \\
\hline CRITICAL & $\begin{array}{l}\text { "You didn't explain where and how he got his set } \\
\text { of skills .. i was here for tht .. i wanna know how } \\
\text { accurate batman begins was regarding this } \\
\text { aspect." (Sahaj Kuldeep) } \\
\text { "Batman is the worst marvel villain ever iron man } \\
\text { is better." (super awesome fun dude) - irony } \\
\text { "BATMAN > MARVEL ... BATMAN > DC ... } \\
\text { BATMAN > AVENGERS .. BATMAN > UFC ... } \\
\text { BATMAN > OBAMA ... BATMAN > HITLER ... } \\
\text { BATMAN > SATAN." (Brujo Hernandez) } \\
\text { "I love Bataman but this and Superman's origins } \\
\text { are the two most over-told origin stories in the } \\
\text { history of comcs. LOL." (spacejords) }\end{array}$ & $\begin{array}{l}\text { "lol green arrow is so lame. Thats why Batman } \\
\text { can beat his ass while holding back." (Thierry } \\
\text { Saint-Jour) } \\
\text { "Green Arrow is a Batman wannabe. He is a } \\
\text { billionaire playboy vigilante, he had a different } \\
\text { childhood than Bruce's but another thing they } \\
\text { have in common is naming all they own after } \\
\text { themselves, like the Batmobile, Arrowmobile, } \\
\text { Batcave, Arrow-den or whatever it's called, he } \\
\text { should've named those things in relation to his } \\
\text { skills, like his 'Arrow den' should've been." } \\
\text { (PixelFoundry Gaming) } \\
\text { "Green Arrow, a guy when shoots people with } \\
\text { arrows a night, doesn't like gunds. Really? } \\
\text { Someone should fire that writer." (Brooks } \\
\text { Gordon) }\end{array}$ \\
\hline $\begin{array}{l}\text { DISAWOVING } \\
\text { (trolling) }\end{array}$ & $\begin{array}{l}\text { "Most. Annoying. And. Butthurt. Fanboydom. } \\
\text { Ever." ((OSanoBR) } \\
\text { "I'd say vote up if your a batman fan but then I'd } \\
\text { get approvals up the ass, so just vote up if you } \\
\text { think he's overrated." (Andrew-V/Ellnats) }\end{array}$ & $\begin{array}{l}\text { "Arrow is awsome tv show, one of the best tv } \\
\text { shows i have ever seen. In my opinion it is even } \\
\text { better than game of thrones. Anyway i dont } \\
\text { give a fuck about comic book version of green } \\
\text { arrow. The comic book origin story presented } \\
\text { here sucks so bad." (Tesseract9630) }\end{array}$ \\
\hline
\end{tabular}

Figure 7: Categories of user reactions to the comic book superhero origin videos

As mentioned earlier there are many other ways to categorize user reactions to popular cultural content on the Internet. Some of these categories can be found or extrapolated from Nancy Baym's study of american soap opera tv-series from the 1990'ies (Baym, 2000), or Henry Jenkins' study of the LGBT fan community of long running tv-series such as Star Trek (Jenkins, 1992) or in fact any study on fan-based participatory culture. The point in this context is to understand what kind of role the user reactions play in WatchMojo.com's productions and re/tellings of comic book superhero origins. 
The user reactions celebrating the origin videos echo the fan spirit and fascination of the superhero characters. This, of course, functions as a support for the WatchMojo.com production of the videos, but it also contributes to the pathos of the genre. Celebrating comic book superhero origin stories mark support, and give both WatchMojo.com and the other users following the channel to maintain a sense of community.

The user reactions elaborating on the videos function as a way of the users to demonstrate their ability to categorize, compare and review different characters and storylines. In this respect elaborating on concrete videos and characters demonstrates a reflection of the users' taste, and thus contributing to their "cultural capital". The elaborations may also serve as a way for the users themselves to create readings that include the crossmedia and transmedia representations of the characters and their storylines.

The user reactions speculating on aspects not apparent in the videoes serves as a kind of elaboration, but represents a different kind of involvement, which in turn contributes to both the logos and pathos of the content shared on the channel. In the case of Batman the user JIROU NEGRO wonders why an intellectual and scientific character like Bruce Wayne does not become "truly" super. Speculation in this sense serves as an invitation for other users to take part in the construction of new interpretations of the characters, and thus taking part of the hermeneutical work of the comic book superheroes. The user BigDapPacino has an interesting speculation, hinting at Batman as being homosexual. In the case of Batman the theme of homosexuality has been discussed for decades in fan discourse and communities, though Batman never actually has acted as a homosexual. Hower, in fandom communities many of the comic book superheroes are presented in such acts, not to mock the characters, but instead to contribute to the complexity of the characters. This issue of homosexuality is analysed and discussed in many contemporary academic articles (Gareth, 2010; Spieldenner, 2013).

The users reacting in a critical reflective manner are also elaborating on the video content and the universe of the comic book superheroes. The critical user reactions selected in this context are both ironic (do not take it too serious, you guys), but also mocking (super awesome fun dude). The critical user reactions also seem to employ reference to real world experience (posting of user Brooks Gordon). It can be argued that critical user reactions take a "smart model user" perspective, to use Eco's notion, not accepting the imaginary and fictional grounds of the comic book superhero universe, but instead evaluating the form and the reference of the posting in relation to the world outside the universe of comic book superheroes.

Finally, the disawoving user reactions represent a more radical critical position in relation to the content. However, the disawoving user reactions are rare because they stand out in the overall discourse of the users, and because the break the playful air of the community constructed by the total amount of user reactions and interactions. Disawoving user reactions point beyond the content and the universe of comic book superheroes, and may possibly be a voice of "bad consciousness", because interacting with comic book characters seems as a silly thing to do, when real life confronts the users with many more pressing problems and issues.

As pointed out earlier, user reactions are essential for the work of the video channel. The reactions function as another part of the "engine" making it possible to comment on popular cultural and comic book superhero Internet content. Understanding the user reactions also provide an insight into the lines and discourses of fan community in general.

\section{Report! Concluding observations}

Why are Internet users and fans of comic book superheroes (both digital on the Internet, but also "retro style" browsing through digital comic books) interested in how their superheroes came into existence and became who they are? Secondly, how are we to understand the significance of this particular Internet content produced for the commentary video channel WatchMojo.com? These were the two questions framing this study of comic book superhero origin stories. 
The analysis provides some evidence of the claim that superhero origin stories contribute to identity formation, a sense of belonging and the enabling of categorizing cultural content. The evidence for this is to be found in Eco's notion of the "model reader", adapted in this context to the "model user", and in the user reactions analyzed with the Pentagon model. But the strongest evidence to the claim that the origin stories contribute to identity formation etc is the pragmatic or rather humble hermeneutic approach of the channel WatchMojo.com. The phrase "do you agree" is a sign of this, and at the same time an open invitation to contribute to the continuous retelling of the origin stories.

The analysis furthermore points to the function, that origin stories themselves are important guiding points in a universe of diverse and changing continuities and revisions of the comic book superheroes in the context of crossmedia cultural production. The need for the stories to be revisited and retold happens in the context of the market for culture and experiences. To the question if the Internet as medium plays any part in the continuous and renewed interest for comic book superhero content, the analysis points to the rhetorical work of the channel WatchMojo.com. As the channel states, new videos are created every day. This production spawns new interpretations based on user reactions (and interactions, though not analysed directly in this article), and the channel calls to the users for them to suggest new comic book superheroes that need an origin story told.

One question that the analysis is not able to answer is why the users or the channel are not dealing with the types of origin of the comic book superheroes. As demonstrated users compare the superheroes (here Batman and The Green Arrow), but the significance of the types of origin is not reflected in any direct sense either in the video content or the user reactions. Answering the question of origin types could provide some insight into part of the identity formation of the users. The experience of loss, or abandonment, prejudice, estrangement, accident or misfortune could be viewed as powerful motifs for identity formation and for the fascination of certain comic book superhero characters. This question would be interesting to explore in detail in another study.

Based on the analysis this study claims that both the video form and the form of narrative can be generalized to other Internet content that focus on popular and fan culture. An example would be the "From 1 to 60 years of Arnold Schwarzenegger" (or Jean Claude van Damme or Sylvester Stallone). It is a different video format but the theme of origin (and the focus on bodily abilities) is the same.

\section{Acknowledgements}

I would like to thank my colleagues Thessa Jensen, associate professor, and Peter Vistisen, assistant professor, for their support, and their interest into the "über human" world of bow wielding, line swinging and shield throwing characters. I would also like to thank my colleague Bo Allesøe Christensen, assistant professor, for helping me with the final touches on the reviewed article. Finally I would like to thank Raymond Kight for his help with the initial manuscript and his insights into the American market of comic book superheroes. 


\section{References}

Andersen, T. F. (2012). Thomas Ziehe: Ungdom som optik til at forstå modernisering af kultur (Thomas Ziehe: Understanding the modernization of culture through youth). In: Michael Hviid Jacobsen \& Anders Petersen: Samfundsteori \& Samtidsdiagnose: En introduktion til sytten nyere samfundstænkere for det pædagogiske felt. København: Unge Pædagoger.

Baym, N. (2000). Tune in, log on. Soaps, fandom, and online community. Thousand Oaks, California: Sage Publications.

Beaty, B. \& Woo, B., eds. (2016). The Greatest Comic Book of All Time. Symbolic Capital and the Field of American Comic Books. SpringerLink.

Brooker, W. (2013). Fandom and Authorship. In Charles Hatfield, Jeet Heer, and Kent Worchster: The Superhero Reader. University Press of Mississippi.

Burgess \& Green (2009). YouTube: Online Video and Participatory Culture. Polity.

Christiansen, H-C. et al. (1999). Tegneserier (Comic Books). In: MedieKultur: Journal of media and communication research No. 30. SMID: Aarhus Universitet.

Cohen, S. (1987). Folk Devils and Moral Panics. The creation of the Mods and Rockers. London: Routledge (2011).

Coogan, P. (2006). Superhero. The Secret Origin of a Genre. Austin: MonkeyBrain Books.

Drotner, K. (1999). Dangerous Media? Panic Discourses and Dilemmas of Modernity". In Paedagogica Historica. Routledge.

Duncan, R., Smith, M. J. \& Levitz, P. (2015). The Power of Comics. History, Form, and Culture. London: Bloomsbury Academic. 2nd edition.

Eco, U. (1984). The Role of The Reader. Explorations in the Semiotics of Texts. Bloomington: Indiana University Press.

Fiske, J. (1987). Television Culture. London: Routledge.

Garrett, G. (2007). Holy Superheroes!: Exploring the Sacred in Comics, Graphic Novels, and Film. Westminster John Knox Press. p. 216. ISBN 0-664-23191-8.

Glaser, B. G. \& Strauss, A. L. (1967). The Discovery of Grounded Theory. Strategies for Qualitative Research. Chicago: Aldine Publishing Company.

Hatfield, C., Heer, J., \& Worcester, K. eds. (2013). The Superhero Reader. University Press of Mississippi. Haxthausen, T. (1955). Opdragelse til terror (Education for Terror). Forlaget Fremad.

Heer, J. \& Worcester, K. eds. (2005). Arguing comics: Literary masters on a popular medium. University Press of Mississippi.

Jacobs, W. \& Jones, G. (1985). The Comic Book Superheroes, from the Silver Age to the Present. New York: Crown Publishers.

Jenkins, H. (1992). Textual Poachers. Television Fans \& Participatory Culture. London: Routledge.

Jenkins, H. (2006). Convergence Culture. Where Old and New Media Collide. New York University Press. 
Jensen, T. \& Vistisen, P. (2013). Tent-Poles of the Blockbuster. How Transmedia Storytelling can Spin off a Mainstream Blockbuster. In Academic Quarterly Vol. 7 (p. 237-248).

Kaveney, R. (2008). Superheroes! Capes and Crusaders in Comics and Films. London: I.B. Tauris.

Knowles, C. (2007). Our Gods Wear Spandex: The Secret History of Comic Book Heroes. Weiser.

Wandtke, T. R., ed. (2007). The amazing transforming superhero! Essays on the revision of the characters in comic books, film and television. North Carolina: McFarland \& Company, Inc. Publishers.

Schott, G. (2010). From fan appropriation to industry re-appropriation: the sexual identity of comic superheroes. In: Journal of Graphic Novels and Comics, Vol. 1, No. 1, p. 17-29.

Spieldenner, A. R. (2013). Altered egos: gay men reading across gender difference in Wonder Woman. In: Journal of Graphic Novels and Comics, Vol. 4, No. 2, p. 235-244.

Strömberg, F. (2016). Comics studies in the Nordic countries - field or discipline? In: Journal of Graphic Novels and Comics, Vol. 7, No. 2, p. 134-155.

Voelker-Morris, R. \& Voelker-Morris, J. (2014). Stuck in tights: mainstream superhero comics' habitual limitations on social construction of male superheroes. In: Journal of Graphic Novels and Comics, Vol. 5, No. 1, p. 101-117.

Wandtke, T. R., ed. (2007). The Amazing Transforming Superhero! Essays on the Revision of Characters in Comic Books, Film and Television. London: McFarland \& Company, Inc.

Žižek, S. (1989). The Sublime Object of Ideology. London: Verso.

Žižek, S. (2000). The Art of the Ridiculous Sublime: On David Lynch's Lost Highway. Washingon: University of Washington Press.

\section{Web citations}

Wikipedia. The Free Encyclopedia. (2017, July 5). Retrieved from

https://en.wikipedia.org/w/index.php?title=Main Page\&oldid=794891270

WatchMojo.com. (2017, July 5) Retrieved from http://www.watchmojo.com/corporate/stats.php

WatchMojo.com on YouTube. (2017, July 5). Retrieved from https://www.youtube.com/user/WatchMojo/ 